\title{
Preconception nutritional intake and lifestyle factors: first results of an explorative study
}

\author{
Sabina de Weerd ${ }^{\mathrm{a}, \mathrm{b}}$, Eric A.P. Steegers ${ }^{\mathrm{a}, \mathrm{b}}$, Mirjam M. Heinen ${ }^{\mathrm{c}}$, Sharon van den Eertwegh ${ }^{\mathrm{c}}$, \\ Rianne M.E.J. Vehof ${ }^{\mathrm{d}}$, Régine P.M. Steegers-Theunissen ${ }^{\mathrm{a}, \mathrm{b}, \mathrm{e}, *}$ \\ ${ }^{a}$ Department of Obstetrics and Gynecology, Erasmus Medical Center Rotterdam, P.O. Box 2040, 3000 CA Rotterdam, The Netherlands \\ ${ }^{\mathrm{b}}$ Department of Obstetrics and Gynecology, University Medical Center Nijmegen, P.O. Box 9101, 6500 HC Nijmegen, The Netherlands \\ ${ }^{\mathrm{c}}$ Department of Nutrition and Dietetics, Arnhem-Nijmegen University of Professional Education, 6503 GL Nijmegen, The Netherlands \\ ${ }^{\mathrm{d}}$ Department of Nutrition and Dietetics, University Medical Center Nijmegen, P.O. Box 9101, 6500 HC Nijmegen, The Netherlands \\ ${ }^{\mathrm{e}}$ Department of Epidemiology and Biostatistics, University Medical Center Nijmegen, P.O. Box 9101, 6500 HC Nijmegen, The Netherlands
}

Received 13 January 2003; received in revised form 2 April 2003; accepted 5 May 2003

\begin{abstract}
Objective: To describe nutritional intake and lifestyle factors in women planning pregnancy. Study design: A semi-quantitative, 1-month food frequency questionnaire and a questionnaire on health practices and personal views were filled out at home and verified by telephone interview. Results: One hundred and one women agreed to participate and data of 69 women were eligible for evaluation. Women planning pregnancy $(n=46)$ consumed significantly more saturated fats and proteins, less carbohydrates and higher median intakes of Vitamin A, thiamin, riboflavin, calcium, selenium, magnesium and iron than controls $(n=23 ; P<0.05)$. However, the percentage of women planning pregnancy with intakes below recommended dietary allowances was $74 \%$ for iron, $59 \%$ for selenium, $48 \%$ for Vitamin A and $91 \%$ for copper. Ninety-six percent and $20 \%$ of them reported alcohol use and smoking, respectively. Conclusions: Nutritional intake of women in the preconception period appears to be inadequate. Efforts to increase awareness of a healthy diet and lifestyle before and throughout pregnancy should be continued.
\end{abstract}

(C) 2003 Elsevier Ireland Ltd. All rights reserved.

Keywords: Maternal nutrition; Screening; Preconception counseling; Food frequency questionnaire

\section{Introduction}

The preconception period continues to gain recognition as an ideal opportunity to optimize the health of the mother-tobe. Important lifestyle factors that could be subject to intervention before pregnancy include prenatal alcohol use, smoking and malnutrition [1,2]. Moreover, poor maternal nutritional intake during pregnancy has been associated with offspring suffering from diabetes mellitus and cardiovascular diseases in later life [3]. Since a number of nutritional and lifestyle factors for poor pregnancy outcome are modifiable, obstetricians and other health care providers should aim to optimize women's health before conception. Recent data from national health surveys indicated that in the general population nutritional intake is suboptimal, and that virtually the entire Dutch population suffers to some extend from deficiencies of essential vitamins, minerals, and

\footnotetext{
${ }^{*}$ Corresponding author. Tel.: +31-24-3619132; fax: +31-24-3613505. E-mail address: r.steegers@epib.umcn.nl (R.P.M. Steegers-Theunissen).
}

trace elements $[4,5]$. As a poor nutritional status may lead to serious health problems [5], it may also have in (pre)pregnant women adverse consequences for maternal health and that of her offspring. Therefore, the quality of the maternal diet should receive special attention before a woman conceives $[3,6]$.

Before well-defined nutritional interventions can be considered, however, the nutritional intake and habits in women of reproductive age, especially among those who are currently planning a pregnancy, need to be further explored. We evaluated the nutritional intakes and lifestyle factors in women currently planning pregnancy and in a control group of women of comparable age. The nutritional intakes were compared to both the Dutch recommended dietary allowances (RDA) and to the guidelines for adequate diet. In addition, we evaluated whether women planning pregnancy also prepare themselves for pregnancy by adjusting their nutritional intake and lifestyle. By asking women to rate their diet and lifestyle, their personal views and knowledge of health practices were also assessed. 


\section{Materials and methods}

\subsection{Study design}

This explorative study was a collaborative project between the Department of Obstetrics and Gynecology, Department of Epidemiology and Biostatistics, and Department of Nutrition and Dietetics of the University Medical Center Nijmegen in The Netherlands. Between January and June 2001, women of reproductive age in Nijmegen and surrounding regions were recruited through advertisements in local newspapers, posters at health clinics and day care centers, and by word of mouth. A research fellow in preconception care and two dieticians in training carried out the study. Women who were already pregnant, who were breastfeeding or who followed an ethnic diet (i.e. Turkish) were excluded.

\subsection{Instruments}

A validated semi-quantitative food frequency questionnaire (FFQ) was used to estimate the intake of energy, total and saturated fats, total protein, mono- and disaccharides, polysaccharides (complex carbohydrates) and vitamins, minerals and trace elements from foods consumed in the past month $[7,8]$. Information on demographic characteristics including age, height, weight, educational background, current profession, prior pregnancy, and lifestyle factors including alcohol and tobacco use, was obtained by a separate questionnaire. In this questionnaire, data were also collected on perceived health (scale range from 1-10), diet (vegetarian, calorie-restricted), past and current vitamin supplement use and satisfaction with body weight. Personal views were assessed by the following questions: whether women considered their dietary habits to be healthy (yes/ no), what could be done to improve them (open-ended), and whether they completely agree, agree, disagree, or completely disagree with several statements such as "I should eat less fat". Volunteers received the questionnaires and were asked to fill out and return them within 2 weeks. The completed and returned forms were verified by telephone interview. Participants were offered the opportunity to be informed about their evaluated nutritional intake and habits.

\subsection{Statistical analysis}

The data obtained by the FFQ was converted into standardized portions, weights and products using the Dutch nutrient database "NEVO" [9]. Subsequently, the report "Portion sizes, weights and food code numbers" [10] was used to calculate average daily dietary intake. The food codes were entered into the software program Becel-5 (Rotterdam, Netherlands, 1996) [11], which was used to calculate the intakes of macronutrients and retinol, $\beta$-carotene, ascorbic acid, tocopherol, cholecalciferol, thiamin, riboflavin, niacin, pyridoxine, biotin, potassium, calcium, phosphorus, iron, magnesium, zinc, selenium and copper intake. The Becel-5 program could not calculate the dietary intakes of folate and cobalamin.

The median energy and nutrient intakes of women who were planning pregnancy and controls were calculated using SPSS 9.0 and 10.1. Demographic characteristics, total energy, macro- and micronutrient intakes of the two study samples were compared by the Mann-Whitney $U$ and Kruskall-Wallis tests. Macronutrient intakes were calculated in percentages in order to adjust for total daily energy intake. The number of women planning pregnancy whose diet contained less than the minimum requirements or higher amounts than the maximum recommended intake for each nutrient as defined by the Dutch recommended dietary allowances (RDA) was calculated and reported in the tables. The RDA is the average requirement \pm 2 S.D., defined as the level of intake that is adequate for almost the entire population $[12,13]$. Statistical significance was defined by $P \leq 0.05$.

\section{Results}

\subsection{Characteristics of women}

Among the 101 women who volunteered to participate, $72 \%$ completed and returned the questionnaires. Four women were excluded: one was pregnant, one post-menopausal, and two could not be reached by telephone to verify the answers of the questionnaires. This resulted in the evaluation of 69 women between 18 and 45 years of age, of which 46 were currently planning a pregnancy, and 23 who indicated not to be planning to conceive served as controls. Women who were planning pregnancy were significantly older than controls, median age 31.5 and 28.0 years, respectively. Half of them were planning a first pregnancy. Demographics and use of vitamin supplements were not significantly different between the groups (Table 1).

Table 1

Demographic and lifestyle characteristics of women planning pregnancy and controls

\begin{tabular}{|c|c|c|}
\hline Characteristic & $\begin{array}{l}\text { Women planning } \\
\text { pregnancy }(n=46)\end{array}$ & $\begin{array}{l}\text { Control women } \\
(n=23)\end{array}$ \\
\hline Age $(\text { years })^{a}$ & $31.5(19-45)$ & $28.0(18-43)^{*}$ \\
\hline $\mathrm{BMI}^{\mathrm{a}}$ & $23.2(18.3-30.1)$ & $21.9(17.8-30.1)$ \\
\hline Never pregnant $(\%)$ & 50 & 65 \\
\hline \multicolumn{3}{|l|}{ Educational background (\%) } \\
\hline Low & 2 & - \\
\hline Middle & 38 & 30 \\
\hline High & 60 & 70 \\
\hline $\begin{array}{l}\text { Folic acid or multivitamin } \\
\text { supplement use }(\%)\end{array}$ & 48 & $52^{\mathrm{b}}$ \\
\hline
\end{tabular}


Table 2

Questionnaire items pertaining to alcohol intake and smoking

\begin{tabular}{|c|c|c|}
\hline Question $^{\mathrm{a}}$ & $\begin{array}{l}\text { Women planning } \\
\text { pregnancy, } N\end{array}$ & $\begin{array}{l}\text { Control } \\
\text { women, } n\end{array}$ \\
\hline \multicolumn{3}{|l|}{ Do you smoke? } \\
\hline Yes & 5 & 2 \\
\hline No & 37 & 18 \\
\hline Sometimes & 4 & 3 \\
\hline \multicolumn{3}{|l|}{ Please mark which tobacco products } \\
\hline Cigarettes & 7 & 4 \\
\hline Cigars & 2 & 1 \\
\hline Marijuana & - & - \\
\hline How many cigarettes daily? ${ }^{\mathrm{b}}$ & $5.5(1-20)$ & $8.5(0-22)$ \\
\hline \multicolumn{3}{|c|}{ Did you smoke during your last pregnancy ${ }^{\mathrm{c}}$} \\
\hline Yes & 2 & - \\
\hline No & 3 & - \\
\hline How many cigarettes daily? & $2-5$ & - \\
\hline \multicolumn{3}{|l|}{ Do you drink alcohol? } \\
\hline Yes & 12 & 4 \\
\hline Sometimes & 21 & 8 \\
\hline Rarely & 11 & 8 \\
\hline Never & 2 & 3 \\
\hline \multicolumn{3}{|l|}{ How often do you drink alcohol? } \\
\hline 1-3 times per month & 20 & 11 \\
\hline 1-2 days per week & 12 & 6 \\
\hline 3-4 days per week & 3 & - \\
\hline 5-6 days per week & 4 & 1 \\
\hline 7 days a week & 1 & - \\
\hline \multicolumn{3}{|l|}{ How many glasses of alcohol weekly? } \\
\hline $1-3$ per week & 10 & 4 \\
\hline 4-6 per week & 5 & 1 \\
\hline $7-10$ per week & 5 & 1 \\
\hline More than 10 per week & - & - \\
\hline \multicolumn{3}{|c|}{ Did you drink during your last pregnancy? ${ }^{\mathrm{c}}$} \\
\hline yes & 5 & 1 \\
\hline No & 15 & 6 \\
\hline If so, how many glasses daily? ${ }^{\mathrm{b}}$ & $5(1-5)$ & - \\
\hline
\end{tabular}

${ }^{a}$ Not all questions were applicable to all women.

${ }^{\mathrm{b}}$ Median (range).

${ }^{c}$ Of the 23 women who had been pregnant previously.

Seven of all women reported to consume an alternative diet, of which five were vegetarian, one vegan, and one woman ate only biological products. Nine women planning pregnancy (20\%) and five controls (22\%) reported to smoke. Almost all of the women planning pregnancy reported some degree of alcohol use (Table 2), and $11 \%$ of them consumed an average of 7-10 glasses of alcohol per week. Additional data on alcohol intake and smoking are shown in Table 2.

\subsection{Nutritional intake $(F F Q)$}

The intake of nutrients in women who were planning pregnancy, controls, and the recommended dietary allowances (RDA) for the Dutch population of women aged 22-50 years are shown in Table 3. Median energy intake of women planning pregnancy and controls exceeded RDA by more than $300 \mathrm{kcal}$ per day, 2387 and $2407 \mathrm{kcal}$ per day, respectively. All but one of the women planning pregnancy consumed an excessive amount of saturated fats and only two control women consumed diets containing less than $10 \%$ saturated fat daily (Table 3 ). Median daily protein intake was significantly higher among women planning pregnancy than controls (16\% versus $14 \% ; P \leq 0.05)$. Total daily intake of complex carbohydrates was significantly lower among women planning pregnancy than controls, 44 and $48 \%$, respectively. The average daily consumption of fruits (1.5 pieces) and vegetables (2.5 servings) was below the recommended daily portions for both study groups. The low intake of complex carbohydrates was due to a low consumption of bread, with an average of 4.5 slices daily (recommended: 5-7 slices), as well as of potatoes, rice and pastas ( 2.5 spoonfuls instead of the recommended 3-5 per day).

Women planning pregnancy had significantly higher median dietary intakes of the micronutrients vitamin A (retinol $+[\beta$-caroteen $/ 6])$, thiamin, riboflavin, calcium, selenium and magnesium than controls (Table 4). The number of women planning pregnancy who had a deficient intake, i.e. who did not meet the minimum RDA for each micronutrient, is also shown in Table 4. Daily intake of Vitamin A was below RDA in $48 \%$. Cholecalcipherol intake was deficient in $26 \%$, dietary iron intake deficient among $74 \%$ and selenium intake deficient among 59\% of women planning pregnancy. Less than $10 \%$ met the RDA

Table 3

Daily median energy intake (Kcal) and fat, protein and carbohydrate intake (en\%) among women planning pregnancy and controls

\begin{tabular}{lcccc}
\hline Macronutrient & RDA & $\begin{array}{l}\text { Women planning pregnancy } \\
(n=46), \text { median (range) }\end{array}$ & $\begin{array}{l}>\text { RDA }^{\mathrm{a}}, \\
N(\%)\end{array}$ & $\begin{array}{l}\text { Control women } \\
(n=23), \text { median (range) }\end{array}$ \\
\hline Energy (kcal) & 2071 & $2387(1350-3305)$ & $33(72)$ & $2407(1475-4115)$ \\
Fat (en\%) & $20-40$ & $39(30-54)$ & $16(39)$ & $36(28-49)$ \\
Saturated fat (en\%) & $\leq 10$ & $15(10-26)$ & $45(98)$ & $13(8-22)^{*}$ \\
Protein (en\%) & $10(\leq 25)$ & $16(12-21)$ & $0(0)$ & $14(10-18)^{*}$ \\
Carbohydrates (en\%) & $\geq 40$ & $44(33-54)$ & $11(24)$ & $48(37-62)^{*}$ \\
Mono-/disaccharides (en\%) & $15-25$ & $19(12-31)$ & $8(17)$ & $23(4-47)^{*}$ \\
\hline
\end{tabular}

RDA: recommended dietary allowance for Dutch non-pregnant women aged 22-50 years [12]. en\%: Percent of total energy intake.

${ }^{*} P<0.05$, Mann-Whitney $U$ test; women planning pregnancy vs. controls.

${ }^{a}$ Number $(\%)$ of women with an unbalanced diet, i.e. either exceeding the maximum or below the RDA, are shown. 
Table 4

Median daily intake of vitamins and minerals from diet among women planning pregnancy and controls

\begin{tabular}{|c|c|c|c|c|c|}
\hline Micronutrient & RDA & $\begin{array}{l}\text { Women planning pregnancy } \\
(n=46), \text { median (range) }\end{array}$ & $\begin{array}{l}<\mathrm{RDA}^{\mathrm{a}}, \\
N(\%)\end{array}$ & $\begin{array}{l}\text { Control women }(n=23) \text {, } \\
\text { median (range) }\end{array}$ & $\begin{array}{l}<\mathrm{RDA}^{\mathrm{a}}, \\
N(\%)\end{array}$ \\
\hline \multicolumn{6}{|l|}{ Vitamins } \\
\hline Retinol $+[\beta$-caroteen/6] $(\mu \mathrm{g})$ & 800 & $836(332-1828)$ & $22(48)$ & $628(353-1302)^{*}$ & $15(65)$ \\
\hline Cholecalcipherol $(\mu \mathrm{g})$ & $2.5-5.0$ & $3.9(0.9-6.8)$ & $12(26)$ & $4.0(0.7-6.4)$ & $5(22)$ \\
\hline Tocopherol (mg) & 9.3 & $13.9(5.2-29.8)$ & $9(20)$ & $15.7(6.8-34.0)$ & 4 (17) \\
\hline Thiamin $(\mathrm{mg})$ & 1.1 & $1.4(0.8-2.4)$ & $6(13)$ & $1.1(0.6-2.1)^{*}$ & $9(39)$ \\
\hline Riboflavin (mg) & 1.1 & $1.8(0.9-2.9)$ & $4(9)$ & $1.4(0.8-3.0)^{*}$ & $6(26)$ \\
\hline Niacin (mg) & 13.0 & $16.7(9.5-28.8)$ & $10(22)$ & $14.9(6.7-22.1)$ & $6(26)$ \\
\hline Pyridoxine (mg) & 1.1 & $1.9(1.0-2.6)$ & $1(2)$ & $1.8(1.0-2.6)$ & $2(9)$ \\
\hline Ascorbic acid (mg) & 70 & $142(49-349)$ & $4(9)$ & $115(50-385)$ & $4(17)$ \\
\hline \multicolumn{6}{|l|}{ Minerals } \\
\hline Iron (mg) & 15.0 & $13.6(8.9-30.7)$ & $34(74)$ & $11.5(6.2-25.8)$ & $18(78)$ \\
\hline Calcium (g) & 1.0 & $1.3(0.6-2.5)$ & $10(22)$ & $1.0(0.4-2.0)^{*}$ & $12(52)$ \\
\hline Selenium $(\mu \mathrm{g})$ & $50-150$ & $48(25-74)$ & $27(59)$ & $40(25-55)^{*}$ & $18(78)$ \\
\hline Copper (mg) & $1.5-3.5$ & $1.2(0.6-1.7)$ & $42(91)$ & $1.2(0.6-2.0)$ & $20(87)$ \\
\hline Zinc (mg) & 9.0 & $10.7(7.0-17.6)$ & 7 (15) & $10.0(5.9-15.4)$ & $9(39)$ \\
\hline Magnesium (mg) & $250-300$ & 370 (249-604) & $1(2)$ & $318(151-679)^{*}$ & $1(4)$ \\
\hline
\end{tabular}

RDA: recommended dietary allowance for Dutch non-pregnant women aged 22-50 years [13].

${ }^{*} P<0.05$, Mann-Whitney $U$ test; women planning pregnancy vs. controls.

${ }^{\text {a }}$ Number $(\%)$ of women with a deficient micronutrient intake, i.e. below the RDA, are shown.

for copper. The overall intake of thiamin, riboflavin, niacin and pyridoxine, as well as of Vitamin C was adequate among most women planning pregnancy and controls.

\subsection{Personal views}

Personal views on health and nutrition did not differ significantly between the two subsets of women. Among all women, $23 \%$ of women reported to be unsatisfied with their body weight, $37 \%$ was satisfied and rest ambivalent. Over one-third of all women were currently trying to lose weight. For health and well being, $74 \%$ of women gave themselves an excellent rating of 8 or higher on a 10-point scale, and another $17 \%$ gave themselves a 7 . The lowest rating, reported by $3 \%$ of women, was 4 . A vast majority of women (77\%) answered that they felt their eating habits are healthy. When asked what they would do if they were to improve their diet, $36 \%$ of women reported that they would eat less candy or other snacks, $24 \%$ would eat more vegetables, $20 \%$ would eat more fruit, and $14 \%$ would eat less fatty products such as fries, pizza or Chinese food. Only $32 \%$ of women agreed with the statement 'I should eat less fat', and $57 \%$ agreed with the statement 'I should eat less saturated fats'.

\section{Discussion}

In this explorative study we evaluated nutritional intakes and other lifestyle factors in women of reproductive age and the impact of pregnancy planning. To our knowledge, nutritional intakes of women planning pregnancy have not been evaluated previously. Our preliminary results reflect that an inadequate diet, rich in saturated fats and marginal in a number of essential micronutrients, is very common among women of reproductive age. Overall, pregnancy planning appears not to significantly affect nutritional intake, alcohol use and smoking habits. These data of an imbalance of macro- and micronutrients are supported by others that studied nutritional intakes retrospectively 3 months before pregnancy in a population of Latinas and white non-Latinas [14].

Although virtually all of the women planning pregnancy exceeded the upper limit for saturated fat intake, not even one-third of them acknowledged that they should eat less fats and only half agreed that they should eat less saturated fats. Therefore, we conclude that the women in our study overrated the adequacy of their diets and did not seem to have the knowledge about the contents of foods that they consume. In accordance with data of Dutch women planning pregnancy, less than half of women planning pregnancy reported to take folic acid or another vitamin supplement to reduce the risk of a neural tube defect [15]. The suboptimal intake of several micronutrients and possible implications for the course and outcome of pregnancy, in particular of iron and copper, should be addressed. The deficient iron intake of the majority of potential mothers places these women at risk for developing iron deficiency anemia during pregnancy, resulting in increased risk of complications as preterm delivery, low birth weight and fetal death [16]. As iron supplementation in early pregnancy is not routinely practiced, women should be advised to increase their intake of iron-rich foods, preferably of green leafy vegetables, before entering pregnancy. Maternal copper deficiency has been shown in animal studies to cause brain defects, connective tissue abnormalities, intra-uterine growth 
retardation, birth defects and fetal death [17]. In human pregnancy, however, the relation between deficient copper intake and adverse pregnancy outcome, has not been clarified so far. Likewise, the impact of most maternal nutritional deficiencies on prenatal development remains to be further investigated.

All women should be advised to abstain from drinking in the periconceptional period and throughout pregnancy, since even as little as one drink per week has been associated with adverse effects [18]. In our study, the number of women planning pregnancy who reported some degree of alcohol use $(96 \%)$ was much higher than the reported $49 \%$ in the previously mentioned study [14] and the $53.3 \%$ recently reported among US women of childbearing age [19]. Although a significant number of women may limit or quit alcohol intake as soon as they are aware of their pregnancy, most of them will not realize that they are pregnant in the first most important weeks of embryonic development.

The validity of the nutritional data is always an issue of discussion. However, we used a validated and highly reproducible FFQ and evaluated this data on group level [7,8]. A FFQ was used above the $24 \mathrm{~h}$ recall or food diary method because it covers a longer period (1 month) and may therefore give a better approximation of habitual diet [20]. Moreover, subjects were motivated to participate, reflected by the fact that the majority would like to be informed about their evaluated diet. Nevertheless, overreporting of healthy nutritional habits and an underestimation of undesirable habits cannot be completely ruled out. Such reporting bias may be especially common among women planning pregnancy. It turned out from telephone interview that some women did indeed underreport snack consumption and overestimated their fruit intake in the questionnaires. In order to obtain a population of women of reproductive age preconceptionally, we had to rely on advertisements and active recruitment. Both groups of women were highly educated as compared to the general population, which limits the degree to which our data may be extrapolated to the general population. It cannot be ruled out that highly educated women are more concerned about their nutritional habits and were therefore more willing to participate.

\section{Conclusions}

These preliminary results suggest that women who are planning to conceive are not necessarily preparing themselves for pregnancy by taking dietary or other health promotion measures. Although they have a higher daily intake of several vitamins and minerals compared to other women of reproductive age, overall micronutrient intakes are often below RDA and unhealthy behaviors such as a high saturated fat intake, smoking and alcohol use are even more prevalent among women planning to conceive. In order to educate women about the nutritional requirements of pregnancy and the implications of nutritional status on pregnancy outcome, the adverse effects of smoking and alcohol use and the protective effect of folic acid supplements, we should continue efforts to provide preconception counseling. Future research on dietary practices among women planning pregnancy should focus on women with a lower education and should relate nutrition and other health practices to subsequent pregnancy outcome to assess their impact.

\section{Acknowledgements}

We gratefully acknowledge Mrs. E.L. Rasmussen for her collaboration and input in the study design and Ms. I. Busser for her input in construction of the lifestyle questionnaire and initial recruitment of women.

\section{References}

[1] American College of Obstetricians and Gynecologists. Preconceptional care. ACOG technical bulletin no. 205. Int J Gynaecol Obstet 1995;50:201-7.

[2] Cnattingius S, Bergström R, Lipworth L, Kramer MS. Prepregnancy weight and the risk of adverse pregnancy outcomes. New Engl J Med 1998;338:147-52.

[3] Barker DJP. Fetal origins of coronary heart disease. BMJ 1995; 311:171-4.

[4] Hulshof KFAM, Kistemaker C, Bouman M. The intake of energy and nutrients by Dutch population groups-1997-1998, Dutch Food Consumption Survey. TNO Report V98.805. Zeist: TNO Nutrition and Food Research Institute; 1998

[5] Nieuwenhuis RA. Summary of the report. Nutrition deficiencies in The Netherlands. Available from: http://www.soe.nl/nutrepor.htm.

[6] Reifsnider E, Gill SL. Nutrition for the childbearing years. JOGNN 2000;29:43-55.

[7] Feunekes GIJ, van Staveren WA, de Vries JHM, Burema J, Hautvast JGAJ. Relative and biomarker-based validity of a food-frequency questionnaire estimating intake of fats and cholesterol. Am J Clin Nutr 1993;58:489-96.

[8] Feunekes IJ, van Staveren WA, Graveland F, de Vos J, Burema J. Reproducibility of a semiquantitative food frequency questionnaire to assess the intake of fats and cholesterol in The Netherlands. Int $\mathbf{J}$ Food Sci Nutr 1995;46:117-23.

[9] NEVO-foundation. Dutch food composition table. Netherlands bureau for nutrition education. The Hague, 1998.

[10] Donders-Engelen MR. Portion sizes, weights and food code numbers. Zeist: Wageningen Agricultural University and TNO Nutrition and Food Research Institute; 1997

[11] Becel Food Information Center. Becel food program. Version 5 (software); 1996

[12] Health Council of The Netherlands. Dietary reference intakes: energy, proteins, fats and digestible carbohydrates. The Hague: Health Council of The Netherlands; 2001 (publication no. 2001/19).

[13] Health Council of The Netherlands: Dietary reference values: calcium, Vitamin D, thiamin, riboflavin, niacin, panthothenic acid, and biotin. The Hague: Health Council of The Netherlands; 2000 (publication no. 2000/12).

[14] Schooner DM, Velie EM, Shaw GM, Todoroff KP. Energy and nutrient intakes and health practices of Latinas and white nonLatinas 3 months before pregnancy. J Am Diet Assoc 1998;98: 976-84. 
[15] Bekkers RLM, Eskes TKAB. Periconceptional folic acid intake in Nijmegen, Netherlands. Lancet 1999;353:292.

[16] Murphy JF, O’Riordan J, Newcombe RJ, Coles EC, Pearson JF. Relation of hemoglobin levels in first and second trimesters to outcome of pregnancy. Lancet 1986;1:992-5.

[17] Keen CL, Uriu-Hare JY, Hawk SN, et al. Effect of copper deficiency on prenatal development and pregnancy outcome. Am J Clin Nutr 1998;67(Suppl):1003-11.
[18] Sood B, Delaney-Black V, Covington C, et al. Prenatal alcohol exposure and childhood behavior at age 6 to 7 years. I. Dose-response effect. Pediatrics 2001;108:E34.

[19] Alcohol use among women of childbearing age-United States, 1991-1999. MMWR 2002;51:273-6.

[20] Margetts BM, Cade JE, Osmond C. Comparison of a food frequency questionnaire with a diet record. Int J Epidemiol 1989; 18:868-73. 